\title{
Teacher Education Reform in Urban Educator Preparation Programs
}

\author{
Tachelle Banks ${ }^{1}$ \\ ${ }^{1}$ Department of Teacher Education, Cleveland State University, Cleveland, OH, USA \\ Correspondence: Tachelle Banks, Department of Teacher Education, Cleveland State University, Cleveland, OH, \\ 44115, USA. Tel: 1-216-687-4608. E-mail: t.i.banks@csuohio.edu
}

$\begin{array}{ll}\text { Received: November 11, } 2014 & \text { Accepted: December 16, } 2014 \quad \text { Online Published: February 19, } 2015 \\ \text { doi:10.5539/jel.v4n1p60 } & \text { URL: http://dx.doi.org/10.5539/jel.v4n1p60 }\end{array}$

\begin{abstract}
The majority of teachers in the United States are of a different race, ethnicity, class, gender, and linguistic dominance from that of their students. Teachers are specifically challenged by a variety of racial and ethnic issues as they enter their classrooms. This paper discusses the importance of educator preparation programs devoting attention to reforming preparation programs to include high-need clinical experiences for practicing teacher candidates. To better meet the needs of the nation's future students, especially those in high-need schools, public policymakers and the education community must take collective ownership for recruiting, preparing, and supporting a critical mass of new professional practitioners.
\end{abstract}

Keywords: teacher candidates, teacher preparation programs, urban clinical experiences

\section{Current State of Teacher Preparation}

University- and college-based teacher preparation has now come under fire for its failure to adequately prepare future teachers for the demands of the modern school. Evidence is mounting that teacher quality is the biggest in-school determinant of student achievement. The nation's colleges of education are being scrutinized for the inadequate preparation of teacher candidates. In October 2011, Secretary of Education Arne Duncan noted that two-thirds (approximately 62\%) of new teachers reported feeling unprepared. In addition, recent research indicates that teachers believe they have not been adequately prepared to teach children from cultural and linguistic backgrounds different from their own and that they need to learn more specific skills to do so (Ray \& Bowman, 2003; Ryan, Ackerman, \& Song, 2005).

Teacher education programs are continually scrutinized for a variety of reasons, including two misconceptions commonly held by the general public: 1) people are born to teach and 2) most of the learning about teaching occurs while teaching. These misconceptions led to the investigation of teacher education where several problems were found, including disconnected curricula, lack of cohesiveness among those pursuing teacher licenses, lack of socialization of teachers in pre-service training, separation of theory and practice, and policy controlling decisions rather than what we know about teaching and learning (Darling-Hammond, 2005, 2006; Goodlad, 1991).

Traditional teacher preparation programs prepare teacher candidates to complete coursework on psychological principles, subject matter, and teaching methods before beginning student teaching, providing for a few connections to course content. Mentor teachers are usually selected on an as needed basis, not necessarily on the basis of quality. Teacher candidate field placements vary greatly and tend to be idiosyncratic as opposed to well-crafted experiences that foster skill development and mastery. As a result, prospective teacher candidates learn theory in isolation from practice and typically have brief encounters with classroom practice divorced from theory, which further contributes to the gap between research and practice. These variables culminate to produce teacher candidates who feel unprepared to meet the diverse educational needs of children and youth.

The American Association of Colleges for Teacher Education (AACTE) (2010) suggests that redesigning teacher education licensure programs that incorporate clinically-based programming is critical to the development of effective teacher candidates. Effective teaching has been defined as what teachers should know and be able to do (Ball, 1995; Darling-Hammond, 2005, 2006). Recommendations from the Blue Ribbon Panel on Clinical Preparation and Partnerships for Improved Student Learning specifically calls for making clinical practice (classroom-based experiences) the core of teacher preparation, resulting in the development of effective teachers. This diverges from traditional teacher preparation where the emphasis is on academic preparation and coursework. 
The rationale is that like medical students' residency experiences, prospective teachers need multiple and diverse classroom experiences coupled with rich content and pedagogical coursework. The panel offers 10 "design principles" to guide the creation of clinically-based preparation programs:

1) $\mathrm{P}-12$ student learning is the focal point for design and implementation

2) Content and pedagogy are woven around clinical experiences throughout preparation in coursework, laboratory-based experiences, and school-embedded practice

3) Data is used to judge every element of the preparation program

4) Candidates are prepared to be content experts; know how to teach it; and be innovators, collaborators, and problem solvers

5) Candidates are provided extensive feedback

6) Mentors and supervising teachers are rigorously selected and should be effective practitioners

7) Specific sites are designated and funded to provide classroom-based experiences

8) Technology is used to share best practices and facilitate ongoing professional development

9) Research is conducted on teacher effectiveness, best practices, and preparation program performance to support continuous improvement

10) Partnerships among school districts, teachers' unions, state policymakers, and preparation programs are in place

To better meet the needs of the nation's future students, especially those in high-need schools, public policymakers and the education community must take collective ownership for recruiting, preparing, and supporting a critical mass of new professional practitioners.

\section{Impetus for Change}

There is a national need for quality instruction and teachers within high-poverty, urban schools (McKinney, Haberman, Stafford-Johnson, \& Robinson, 2008). The No Child Left Behind (NCLB) Act orders for highly qualified teachers (HQTs) to be in every classroom, meaning that all classroom teachers must have at least a bachelor's degree, demonstrate subject area competence, and obtain full state licensure and certification. Yet, many of these schools are failing to meet the educational needs of impoverished students, as they tend to fail more often on cognitive assessments in all subject areas as compared to more affluent students. Eckert (2013) found that students in high-poverty schools are the most likely to be taught by teachers with the least teaching experience. Students in these schools are plagued with gang violence, are more likely to experience dropout and teen pregnancy, and have the lowest scores on standardized achievement tests. In addition, schools serving these students tend to lack resources and parental involvement. As previously noted, the goal of NCLB was to place an HQT into every classroom of every school by the end of the 2005-2006 school year; however, schools serving disadvantaged students are less likely to employ HQTs and, therefore, are not close to accomplishing this goal (Eckert, 2013).

Although many teachers have been entering the field, the rates of teacher attrition and retirement have been frustrating the need to maintain a highly qualified teaching staff across the country (Gimbert, Cristol, \& Sene, 2007). Researchers have been addressing the need for providing the nation's urban and rural schools with effective teachers in order to guarantee student academic success and teacher retention. However, many teachers do not want to work in these environments because of the low levels of student achievement, high rates of dropout and teen pregnancy, and high incidence of violence (Gimbert et al., 2007). Half of urban teachers end up leaving the field within the first five years of teaching, due to lack of preparedness for urban teaching, classroom intrusions, student behavior problems, and lack of support from school administration. As a result, these students are taught more often by under-experienced and unprepared teachers (McKinney et al., 2008). Teacher preparation programs should aim to make teacher candidates develop competence in working with diverse student populations.

The most powerful curricular activity within teacher preparation is believed to be situating pre-service teachers' learning in K-12 schools. It is believed that university-based teacher preparation programs are necessary for prospective teachers to teach in urban schools. Montecinos et al. (2011) cite the Chicago and Boston teacher residency programs as the best-known models for effective district-based teacher preparation. They include the seven following principles, based off of these programs, which are considered to be necessary for effective teacher preparation programs: 1) intertwine classroom practice and education theory together in a year-long 
residency; 2) focus on candidate learning alongside a trained, experienced, and well-paid mentor; 3) prepare candidates in cohorts to encourage a professional learning community, promote school change, and raise collaboration; 4) build effective partnerships and draw on community-based organizations to foster a "third space" for teacher preparation; 5) serve school districts by catering to both their curricular goals and instructional approaches as well as their teacher supply problems; 6) support candidates for multiple years once they are hired as teachers of record; and 7) launch incentives and support differentiated career goals to reward and retain accomplished teachers (Montecinos et al., 2011).

Creating equitable opportunities for all students to have teachers who are highly qualified in content-specific subject matter is critical for improved student development and performance. Research has shown that teacher quality is the most accurate indicator of students' achievement rates and academic success; however, many urban districts have problems with obtaining and keeping quality teachers. Colleges of education must make an effort to redesign current teacher education programs to include a detailed framework for the development of future urban teachers. Constructs associated with optimal development of effective teaching in urban schools include characteristics of self-perceived teaching efficacy. Teaching efficacy is defined as teachers' beliefs about their own effectiveness as teachers. If a teacher does not feel confident in her teaching ability, she will not put forth the needed amount of effort in meeting her students' needs. Research has shown that teachers who feel prepared to teach also possess high teaching efficacy (Lee et al., 2012). When teachers have a high sense of teaching efficacy, they manage time and student behaviors more effectively.

Effective teaching has been defined as what teachers should know and be able to do (Ball, 1995; Darling-Hammond, 2005, 2006). Characteristics of effective urban teaching include connecting theory and practice, making students feel needed, gentle teaching in a violent society, persistence, and professional/personal orientation to students, to name a few. When pre-service teachers attempt to student teach in an urban school after being taught from a generic and universal curriculum, they tend to experience culture shock or an unhealthy attitude to "save" their students. It is believed that a rigorous teacher education curriculum should address the difficult content in which urban education occurs. The internship experience (i.e., student teaching) is believed to be the most important part of teacher preparation. The internship experience bridges the gap between theory and deliberate practice and allows pre-service teachers to understand the practical reality of teaching demands (Lee et al., 2012).

The field of education has currently been focused on the "failure" of teacher education programs and the inequitable distribution of teachers. These points especially hold true for schools which serve poor minority students in urban areas who are taught by low quality teachers (Eckert, 2013). Researchers have been struggling with determining how to prepare and keep teachers in the field, as well as how to measure the qualifications of incoming teachers into the field. This lack of knowledge from researchers has created a policy problem which, in effect, continues to cause problems in high-poverty/high-minority schools in the U.S. All students, especially students from underrepresented populations and from low-income backgrounds, deserve effective instruction. Teacher preparation programs have the opportunity to improve teaching effectiveness and quality instruction for all students (Lee et al., 2012).

\section{Impact of Urban Clinical Experiences}

Field experiences allow teacher candidates to apply their pedagogical content knowledge in a variety of settings. As a result, clinical experiences should be adequately intensive and extensive for candidates to show proficiency in their future professional roles. School-university partnerships are believed to be an effective tool in improving teacher preparation, instruction, and student achievement. Teacher educators have yet to find a definite answer of how to design and offer prospective teachers the field experiences that would impact them as well as assist them in becoming better teachers. Teacher education programs differ based on length, relationship between universities and school districts, and integration with teacher preparation coursework. This section reviews the literature that describes the impact of urban clinical experiences on prospective teachers.

Teacher education in the U.S. needs more of a focus on clinical practice, academic content, and professional courses. A clinically-based approach will help prospective teachers to better use what they have learned (Banks, Jackson, \& Harper, 2014). There is paucity for more widespread usage of clinically-based programs to better prepare teachers (Banks et al., 2014). Teacher education programs need to work in partnership with school districts to redesign teacher preparation. This will allow for professional accountability of candidates' effective performance and impact on student learning. There are several design principles for clinically-based programs and a series of strategies to revolutionize teacher education (Singh \& Stoloff, 2006). They include: 
1) More rigorous accountability. All teacher education programs should be accountable for how well they help improve P-12 student learning and address the needs of schools.

2) Strengthening candidate selection and placement. Test scores are not only considered in the selection process, but are key attributes that lead to effective teachers.

3) Revamping curricula, incentives, and staffing, so that practice, content, theory, and pedagogy can be closely coupled.

4) Supporting partnerships, so that teacher preparation programs obtain their fair share of funding from revenues generated to support the development of clinically-based programs.

5) Expanding the knowledge base to identify what works and support continuous improvement, as this information will assist in shaping future research as well as public policies on preparation.

Research has shown that clinical experiences allow for teacher candidates to exhibit an increase in their self-efficacy (Singh \& Stoloff, 2006). There are three factors determined to be most essential for the effectiveness of clinical experiences:

1) Having cooperating teachers and university faculty supervise teacher candidates,

2) Providing more than one field experience, and

3) Making sure teacher candidates receive egalitarian treatment from their supervising teachers.

Singh and Stoloff (2006) found that a majority of the teacher candidates believed the clinical experience changed their beliefs about teaching and learning as well as provided them opportunities to observe models of exemplary practice. They also believed that the experience enhanced their pedagogical knowledge and subject matter knowledge. Less than half of the teacher candidates believed the experience helped them learn the associated characteristics of students with disabilities. A majority of the teacher candidates believed the experience helped them learn classroom management skills, played an important role in their teacher preparation, and sharpened their observational skills as well as increased their confidence in impacting student achievement. Many of the teacher candidates viewed themselves as members of a professional team and felt as if they achieved the same status as their cooperating teacher. Some of the teacher candidates desired to spend more time in their field placement and do more teaching. The study suggests that clinical experience represents a successful practice of teacher preparation; however, the authors believe that teacher candidates need to spend an increased amount of time in the field as well as develop more respectful relationships so that equal status is obtained (Singh \& Stoloff, 2006). The findings also confirm that mentor relationships allow for increased engagement of teacher candidates in instructional planning. Teachers may become more reflective and thoughtful as a result of clinical experiences. They also gain more patience, empathy, and tolerance toward their students, as well as a better understanding of their subject. These experiences also make teacher candidates more intent in staying in the field as compared to teacher candidates who did not have clinical experiences.

McKinney et al. (2008) examined if colleges of educations' internship experience assisted in the growth and improvement of effective urban teachers. This study was conducted in response to the need in the U.S. to recruit and develop teachers, particularly in high-poverty, urban schools. The authors used a one-group pretest-posttest design. A total of 59 student interns participated in the study, and they were placed in urban high-poverty schools in two large metropolitan school districts for their internship experience. The majority of the sample was white, female, had less than three years of teaching experience, and between the ages of 20 to 30 . One group of interns followed a traditional route of teacher preparation which modeled the university supervisor, cooperating teacher, and student intern triad relationship. In this route, student interns observed the classroom teacher for the first two weeks, taught one subject the third week, two subjects the fourth week, and so on. Student interns were required to manage the classroom environment and teach all subject material for two consecutive weeks before control was given back to the cooperating teacher. The other group of interns followed a Professional Development School (PDS) model of teacher preparation which extended to the establishment of a school-university partnership so that teacher candidates would specifically be prepared for the urban school experience. These student interns were trained in Frieberg's (1996) Consistency Management and Cooperative Discipline Project in order to improve and enhance student cooperation and self-discipline. The university supervisor and cooperating teacher worked together to provide interns with significant insight and feedback. Student interns regularly attended workshops and seminars as well as participated in community experiences to better understand the out-of-school life of urban students. The student interns' development on 10 of the 15 effective urban teacher characteristics was measured by the Urban Teacher Selection Interview. The 10 characteristics measured were 1) persistence, 2) value of children's learning, 3) theory to practice, 4) work with at-risk students, 5) approach to children, 6) the bureaucracy, 7) admitting mistakes, 8) teacher success, 9) student success, and 10) planning/organization. 
McKinney et al. (2008) found no significant difference between pretest and posttest scores for student interns on the Urban Teacher Selection Interview after the completion of the traditional internship experience or the PDS at an urban high-poverty school. The study suggests that the significance of a short-term internship may not fully prepare teachers for the urban school experience. Some researchers have found that a lack of expertise and knowledge in how to prepare urban teachers is a reason why there is a shortage in teacher preparation research. The authors note that although the student interns had the tools to work with urban at-risk students, they were not established during actual classroom practice. The study also suggests that the internship experiences may actually deter teacher candidates' commitment and motivation to work in urban schools. The authors state that colleges of education must make an effort to redesign current teacher education programs to include a detailed framework for the development of future urban teachers. Better teacher selection may improve urban schools, as the authors believe that only HQTs should work in high-poverty schools. Educational policymakers and researchers have suggested the recruitment of teachers from underrepresented minority groups in order to better respond to the diversity of our nation's students.

Grande, Burns, Schmidt, and Marable (2009) believe that the focus should be on better preparing prospective white teachers to meet the diverse needs of urban students, as well as attracting HQTs in general. As urban schools are experiencing high levels of teacher turnover and unqualified teachers, Grande and colleagues believe that it is necessary to make changes to the traditional methods of teacher preparation. The researchers reviewed a program developed to increase teacher candidates' willingness to teach in urban schools. They examined a multifaceted approach in investigating candidate willingness to teach in urban schools. A total of 73 undergraduate and graduate teacher education students completed pretest and posttest surveys for Summer in the City (SITC), a paid field experience in a high-need urban school district which was in partnership with a local college. SITC aimed to provide teacher candidates with urban classroom experience to persuade them to work in this setting as well as to provide students with tutoring before state and district final exams in June. Candidates were eligible if they had at least a 2.5 grade point average, were enrolled full-time in an approved teacher preparation program, and successfully completed 60 or more college-level credits. Most of the participants were females who had attended suburban schools when they were younger. A majority of them were seeking certification in either childhood (grades 1-6) or adolescence certification. In addition to the surveys, data was collected through journal entries written by the participants. An orientation was provided by veteran teachers from the district so that the teacher candidates would know how to work with the impoverished students. Tutoring responsibilities were determined by the candidates and their cooperating teachers based on their abilities. Two discussion sessions were also held during the program to troubleshoot areas of concern (this was held midway) and to see what the candidates learned (this was held at the end).

The quantitative survey results showed that candidates who rated their previous urban field experience as extremely positive were significantly more willing to teach in urban schools as compared to students who did not rate their experience as such. Although candidates felt more comfortable teaching students of their own ethnic backgrounds, the difference was not statistically significant in regards to teaching different ethnic groups. Candidates who attended urban schools during their P-12 years were shown to be more willing to teach urban students as compared to candidates who did not attend urban schools. There was no significant change in candidates' willingness to teach in urban schools after completion of SITC. The candidates' journal entries were evaluated qualitatively using a grounded theory approach. They noted both advantages and disadvantages of their own P-12 schooling experience, with one of the urban disadvantages being lack of resources needed for academic success. The candidates noticed negative teacher behaviors (e.g., yelling, lack of classroom management) and did not remember this behavior from their own schooling. One candidate believed that teacher behavior was the reason for low student achievement, while others believed that teachers needed to invest in personal relationships with students. Many candidates believed that urban students failed not because of lack of success, but because of lack of drive or apathetic attitude. Since many students believe that everyone expects them to fail, they usually will not try to achieve academically. The candidates became aware of the cultural differences between them and the students, but did not blame these differences for academic failure. Candidates who attended urban P-12 schools felt as if they had an advantage working in urban schools, having an opportunity to serve as a role model. Since the experience did not lead to increased willingness to teach in urban schools, the authors believe that a field experience in the absence of an affiliated course did not have a positive impact on promoting a positive perspective toward working in urban settings. Grande and colleagues (2009) concluded that urban field experiences are more likely to be effective when supplemented by rich discussions of urban school realities so that stereotypes are not created. 
Eckert (2013) assessed teacher preparation and qualifications in urban schools. The purpose of the study was to measure the quality of teacher preparation to help the research community better understand the preparedness of incoming teachers for high-need, urban schools. She focused her study on 1) teacher efficacy, which recognizes an individual's perceptions of how well-prepared he is to teach; and 2) teacher retention, which recognizes whether a teacher remains in a given school after one year of teaching and how resilient he was during that first year. Eckert conducted a mixed-methods, sequential-explanatory study, in which she collected and analyzed quantitative and qualitative data aimed specifically at answering questions created by the first phase of empirical analysis.

For the quantitative phase, Eckert (2013) used nationally representative survey data from the Schools and Staffing Survey (SASS) (2007-2008), Teacher Follow-Up Survey (TFS) (2009), and the Common Core of Data (CCD), all acquired from the National Center for Education Statistics (NCES). The researcher hypothesized that the findings would reveal a significant, positive relationship between the amount of teacher preparation and the level of teacher efficacy among novice teachers in high-poverty/high-minority schools. She also hypothesized that the findings would reveal a significant relationship between both teacher preparation and teacher efficacy and teacher retention among first-year teachers. The participants included only first-year teachers to reduce inconsistencies (e.g., she could not measure the teachers who left each year). The researcher restricted her quantitative sample to those teachers who began teaching after the school year of 2003-2004.

The major variables Eckert (2013) used for the quantitative studies were 1) high-poverty/high-minority urban school, created through the combination of percentage of students receiving free- and reduced-price lunches, urbanicity, and percentage of minority students in the school; 2) preparation level, created through the combination of self-report information in relation to length of student teaching experience and number of education courses taken; 3) HQT status, which determined if the teacher met the federal requirements of HQT; 4) teacher efficacy, which includes personal teacher efficacy (PTE) (i.e., how prepared a teacher feels to create learning for his students) and general teacher efficacy (GTE) (i.e., a teacher's confidence in his ability to inspire definite success from his teaching irrespective of the context or situation); 5) teacher retention, which measures whether a first-year teacher stayed in the same school into his second year of teaching; and 6) control variables, which included teacher sex, teacher race, highest degree, age, school level, years of teaching experience, and region of the country. The results indicated that the novice sample teachers were less likely to be highly qualified as compared to the full sample teachers. However, these novice sample teachers were more likely than their counterparts to teach in at-risk schools.

The qualitative phase of the study was designed to determine why the research questions were either supported or not supported. Eckert (2013) asked 25 novice teachers to complete an online survey (i.e., SASS); she noted a response bias in her sample. Of these 25 teachers, the author selected 14 for initial phone interviews, and further narrowed her sample through the selection of five teachers for in-person, follow-up interviews. The interviews were analyzed through coding and re-coding using a priori categories drawn from the hypotheses refined during analysis.

The results showed that there was a positive, significant relationship between PTE and level of preparation, meaning that teachers with longer student teaching experiences and more coursework were more likely to have higher self-confidence related to day-to-day teaching tasks. The same applied with GTE, although it was a weaker relationship. There was also a positive, significant relationship between HQT status and PTE, meaning that teachers who were deemed highly qualified (i.e., certified in their subject area) were more likely to be confident in day-to-day teaching tasks; there was no significant relationship between HQT status and GTE. The teachers who were interviewed stated that entirely different sets of experiences were responsible for developing PTE and GTE, with GTE development being based the most on context. There was no relationship between the level of teacher preparation and teacher retention. There was also no relationship between HQT status and teacher retention among first-year teachers in high-poverty/high-minority schools. However, GTE was positively related to teacher retention, meaning that first-year urban teachers with confidence in encouraging positive outcomes from students and overcoming external influences were more likely to remain in their original school after one year of teaching. The interviewed teachers confirmed the quantitative results, stating that teachers with low feelings of GTE were more likely to report feeling powerless or meaningless to students. Eckert (2013) concluded that high-poverty/high-minority schools need to hire teachers who possess the belief of success for students within these schools. 


\section{Challenges}

New teachers need a rigorous clinical element in their preparation if they are to become confident and effective professionals. Clearly, teacher preparation programs have been challenged to expose and refine pre-service teachers' attitudes toward diverse student populations (Case \& Hemmings, 2005; Gay, 2000; Milner, 2005). Given this reality, these programs are researching and sampling tactics to better prepare culturally responsive teachers. These strategies include (a) infusing cultural diversity into courses, (b) requiring urban field experiences, (c) assigning students cultural shadowing partners, and (d) mandating urban community visits (Gay, 2000; Irvine, 2003; Krei, 1998; Ladson-Billings, 1994; Ukpokodu, 2004; Villegas \& Lucas, 2002). Universities must restructure the entire preparation program (all courses) to aid pre-service teachers in bridging subject matter, pedagogical expertise, and cultural diversity (Gay, 2000; Ladson-Billings, 1994; Milner, 2005).

The call for educator preparation programs to confront the challenge of preparing a cadre of predominantly White, middle-class, and female prospective teachers to successfully work with an increasingly diverse population of students from urban areas resonates across the country (Darling-Hammond, 2002, 2006; Galman, Pica-Smith, \& Rosenberger, 2010; Ladson-Billings, 1999; McFadden \& Sheerer, 2006; Risko, 2006; Sleeter, 2008; Villegas, 2007). The constant criticisms of schools, colleges, and education departments (McFadden \& Sheerer, 2006; Risko, 2006; Villegas, 2007) have resulted in U.S. Secretary of Education, Arne Duncan, accusing teacher education programs of doing a mediocre job at best in preparing teachers for the realities of the $21^{\text {st }}$ century classroom (Duncan, 2009). Teachers are entering the profession at a time when teacher education is "under severe if not outright vicious attack" (Villegas, 2007, p. 370). Currently, a major issue confronting America's schools is the lack of teachers capable of successfully teaching in diverse settings (Villegas, 2007; Weisman \& Hansen, 2008). Earlier, Ladson-Billings (2001) urged teacher education programs to begin to examine ways to align their preparation with social and political changes taking place in K-12 institutions.

Researchers have constructively criticized traditional teacher education programs, describing them as limited in their ability to produce HQTs. Some years ago, Haberman (1995) stated that the traditional model of teacher education is actually counterproductive for many teachers, including those working in impoverished areas or diverse settings. Blackwell (2003) and Risko (2006) criticized colleges of education for failure to demonstrate conclusively that certified teachers are more successful in the classroom than non-certified teachers (Blackwell, 2003; Risko, 2006). Researchers have also noted the role of the educator as critical in the development of HQTs. Howard (2007) argued that "change has to start with educators" (p. 18). The reason why some teacher preparation programs are resistant to change is because "what they do is what they have always done" (Ladson-Billings, 2001, p. 7). As the NCES (1999) noted, approximately $80 \%$ of teachers who teach ethnically diverse students suggested feeling unprepared to meet their needs. Farkas, Johnson, and Foleno (2000) explained that the majority of new teachers need additional preparation to confront challenges of the "real" classroom, supporting other accusations in the literature that only a small number of teacher preparation programs train teachers to be successful in diverse settings (Ladson-Billings, 2001; Villegas, 2007; Weisman \& Hansen, 2008). In sum, teacher educators fear being ostracized by their peers and therefore accept a monocultural curriculum (Blackwell, 2003). As a result, teacher education programs fail to meet challenging standards that adequately prepare teachers for the $21^{\text {st }}$ century classroom (Blackwell, 2003; Duncan, 2009; McFadden \& Sheerer, 2006; Risko, 2006; Villegas, 2007).

Researchers are suggesting that program coherence may be critical to teacher preparation, as defined by a program's conceptual and structural features (Darling-Hammond, 2006; Grossman, Hammerness, McDonald, \& Ronfeldt, 2008). Generally, there are critical components implicit in the guiding principles and structure of high-need educational programming that may inform educator preparation program practices in urban areas. These include the following:

- Resources provided to facilitate school-university collaboration, with school and university faculty meeting on an ongoing basis to implement and evaluate the program.

- Program coordination, with faculty meeting on a regular basis to discuss the connections between courses and field experiences and to monitor candidates' progress in the program.

- An emphasis on addressing the diverse needs of an urban student population, with candidates completing course assignments and field experiences in urban schools.

- Supportive learning environment with ongoing advisement and mentoring by coordinators, faculty, and university supervisors. 
- Collaborative community, with supportive and personable instructors and collegiality among students and faculty.

- Ongoing and coordinated field experiences throughout a program with experienced cooperating teachers selected by university supervisors in collaboration with school administrators, cooperating teachers oriented to the program and working closely with university supervisors, and courses that provide structured assignments requiring direct application to the classroom.

- Data-driven model that informs program practices.

To be effectively prepared for high-need schools, prospective candidates will need to:

- Actively learn about the ways schools and communities are socially, economically, politically, culturally, historically, and geographically situated and related.

- Have rich, sustained, first-hand opportunities throughout their program to work with racially/ethnically, economically, and linguistically diverse children in urban and rural schools and neighborhoods.

- Learn that good teaching always begins with seeing each child, fully and fairly, as a multi-dimensional being, an individual with a unique history, hopes, and dreams - a child of promise and possibility.

- Understand the importance of valuing students' cultures and lived experiences—and making space for them in the classroom - while espousing the crucial importance of subject area content as well.

- Rigorously question stereotypical views of children and families who live in urban neighborhoods, and learn to see the assets of the communities rather than the deficits.

- Examine the ways their own racial, cultural, and class identities have shaped their perspectives and, if they have economic and social privilege, analyze the advantages they have enjoyed that may have previously gone unrecognized.

- Examine and critique the sources of economic, racial, gender, and linguistic inequity within schools and communities, and understand how these factors influence students' lived experiences within and outside of the classroom.

- Explore together whether and how educators can and should be part of social movements that seek to overcome racial, economic, and linguistic barriers.

- Focus on urban schools but with interest in collaborating with others who attend to the related needs of rural, small town, and suburban schools.

\section{Future Perspectives}

A well-articulated program is needed, whereby issues of cultural, linguistic, and socioeconomic diversities are examined throughout the entire teacher and leadership preparation curriculum instead of in specialized courses (Villegas, 2007; Villegas \& Lucas, 2002; Zeichner \& Hoeft, 1996). This should be complemented with a commitment to follow-up programs for graduates, which would offer the best hope for moving pre-service teachers and school leaders toward greater cultural, linguistic, and socioeconomic sensitivities (Pohan, 1996; Tillman, 2003). More importantly, teacher educators must examine how their experiences "reflect, confirm, or trouble their understanding of their practices and beliefs" (Galman et al., 2010, p. 226). Research shows that teachers are unprepared to meet the needs of diverse students; the teachers (both in-service and pre-service) themselves have consistently reported feeling unprepared to teach in culturally diverse settings (Ladson-Billings, 2000; NCES, 1999; Rushton, 2000, 2001). Knoblauch and Woolfolk Hoy (2008) confirmed that teachers need more than content knowledge to be affirmed in their practice of teaching students in high-need schools. Without a comprehensive understanding of rural and urban communities, deficit thinking could emerge. As Villegas and Lucas (2002) elaborated,

Teachers [and school leaders] looking through the deficit lens believe that the dominant culture is inherently superior to the cultures of marginalized groups in society. Within this framework, such perceived superiority makes the cultural norms of the dominant group the legitimate standard for the United States and its institutions. Cultures that are different from the dominant norm are believed to be inferior...Such perceptions inevitably lead teachers to emphasize what students who are poor and of color cannot do rather than what they already do well. (p. 37)

Developing educators for rapidly transitioning schools requires a reexamination of the current models of teacher and leadership preparation because "continuing with business as usual will mean failure or mediocrity" (Howard, 2007, p. 17) for the nation's K-12 population, as the data related to racial and cultural achievement gaps 
illustrate (Howard, 2007; NCES, 2005). As efforts to best prepare tomorrow's teachers for diversity are examined, there is general agreement that a culturally competent and responsive pedagogy is a useful approach (Gay, 2000; Irvine \& Armento, 2001; Ladson-Billings, 1994; Obiakor, 2001, 2006, 2008; Siwatu, 2006, 2007; Villegas, 2007; Villegas \& Lucas, 2002).

Ladson-Billings (2001) credited teacher preparation programs for acknowledging the necessity of reform. These programs must be a rigorous, research-based curriculum that requires interns to understand differences in student learning across disciplines instead of relying on one "disconnected course, which often serves as the only exposure pre-service teachers have to witness how students learn" (Blackwell, 2003, p. 363). The difficulties of changing teacher education, however, should not be mistaken with impossibilities (Ladson-Billings, 2001). It is possible for teachers with backgrounds different from their students to provide effective classroom instruction if they approach teaching in a way that is responsive to cultural and linguistic diversities of their students (Gay, 2000). Consequently, it is crucial for educator preparation programs to challenge not only the teaching of academic skills necessary to increase students' learning, but also the provision of multiple experiences requiring pre-service teachers to critically examine issues of culture, linguistic diversity, poverty, and social justice (Darling-Hammond, French, \& Garcia-Lopez, 2002; Obiakor, Grant, \& Obi, 2010). This type of reform offers the best hope for educator preparation programs.

\section{Conclusion}

One of the most pressing issues in urban education is the number of vacancies that go unfilled each year, and the number of teachers assigned to teach in areas where they lack certification. State Departments of Education throughout the nation are partnering with teacher preparation programs to produce a cadre of certified teachers to meet the demand and satisfy the requirements of NCLB legislation. Much has been written about the strengths of traditional teacher education programs, especially those that serve traditional in-service teachers (Darling-Hammond, 2003; Darling-Hammond \& Youngs, 2002). Research in this field clearly indicates that urban areas suffer the most from teacher shortage, teacher under-preparation, limited resources, state takeovers, and high teacher turnover (Anyon, 1997; Kozol, 1991; Yeo, 1997). It is clear, however, that producing more certified teachers under traditional teacher education program models will not necessarily address the issue of teacher shortage in high-need urban and rural school districts.

Finally, thinking differently about educator preparation is incongruent with monolithic programming and relying on single course options to equip prospective teachers with the dispositions necessary for successful teaching in high-need, diverse, urban settings. Research has identified traditional teacher preparation programs at the forefront of the problem for failing to provide the type of transformative experiences critical to developing a cadre of teachers and administrators confidently and effectively prepared to work in urban educational settings. High-need schools require the best, the brightest, and the most committed educators. To that end, all educator preparation programs must increase efforts to attract high-quality candidates who truly care about all children.

\section{References}

AACTE. (2010). Videos from AACTE's 2010 annual day on the hill. Retrieved from $\mathrm{http}$ //aacte.org/digital-media/event-recordings/videos-from-aactes-2010-annual-day-on-the-hill.html

Anyon, J. (1997). Ghetto schooling: A political economy of urban educational reform. New York, NY: Teachers College Press.

Ball, A. F. (1995). Community-based learning in urban settings as a model for educational reform. Applied Behavioral Science Review, 3(2), 127-146.

Banks, T., Jackson, D., \& Harper, B. (2014). Responding to the call to prepare highly effective teacher candidates in the United States: The Curriculum Redesign Effort in Advancing Teacher Education. Higher Education Studies, 4(2), 9-18. http://dx.doi.org/10.5539/hes.v4n2p9

Blackwell, J. (2003). Three steps forward: Adopt a teacher. Childhood Education, 80(1), 28. http://dx.doi.org/10.1080/00094056.2003.10521247

Case, K., \& Hemmings, A. (2005). Distancing strategies: White women preservice teachers and antiracist curriculum. Urban Education, 40(6), 606-626. http://dx.doi.org/10.1177/0042085905281396

Darling-Hammond, L. (2002). Access to quality teaching: An analysis of inequality in California's public schools. Stanford, CA: Stanford University.

Darling-Hammond, L. (2003). Keeping good teachers: Why it matters, what leaders can do. Educational Leadership, 60(8), 6-13. 
Darling-Hammond, L. (2005). New standards and old inequalities: School reform and the education of African American students. In Joyce E. King (Ed.), Black education: A transformative research and action agenda for the new century (pp. 197-223). Mahwah, NJ: Lawrence Erlbaum.

Darling-Hammond, L. (2006). Constructing $21^{\text {st }}$-century teacher education. Journal of Teacher Education, 57(3), 300-314. http://dx.doi.org/10.1177/0022487105285962

Darling-Hammond, L., French, J., \& Garcia-Lopez, S. (2002). Learning to teach for social justice. New York: Teachers College Press.

Darling-Hammond, L., \& Youngs, P. (2002). Defining "highly qualified teachers": What does "scientifically-based research" actually tell us? Educational Researcher, 31(9), 13-25. http://dx.doi.org/10.3102/0013189X031009013

Duncan, A. (2009). Teacher preparation: Reforming the uncertain profession. Presentation at the Teachers College, Columbia University, New York, NY. Retrieved from http://ed.gov/news/speeches/2009/10/10222009.html

Eckert, S. A. (2013). What do teaching qualifications mean in urban schools? A mixed-methods study of teacher preparation and qualification. Journal of Teacher Education, 64(1), 75-89. http://dx.doi.org/10.1177/0022487112460279

Farkas, S., Johnson, J., \& Foleno, T. (2000). A sense of calling: Who teaches and why. New York, NY: Public Agenda.

Frieberg, H. J. (1996). From tourists to citizens in the classroom. Educational Leadership, 54(1), 32-36.

Galman, S. A., Pica-Smith, C., \& Rosenberger, C. (2010). Aggressive and tender navigations: Teacher educators confront whiteness in their practice. Journal of Teacher Education, 61(3), 225-236. http://dx.doi.org/10.1177/0022487109359776

Gay, G. (2000). Culturally responsive teaching: Theory, research, \& practice. New York, NY: Teachers College Press.

Gimbert, B. G., Cristol, D., \& Sene, A. M. (2007). The impact of teacher preparation on student achievement in algebra in a "hard-to-staff" urban preK-12-university partnership. School Effectiveness \& School Improvement, 18(3), 245-272. http://dx.doi.org/10.1080/09243450601147528

Goodlad, J. (1991). Why we need a complete redesign of teacher education. Educational Leadership, 49(3), 4-10.

Grande, M., Burns, B., Schmidt, R., \& Marable, M. A. (2009). Impact of a paid urban field experience on teacher candidates' willingness to work in urban schools. Teacher Educator, 44(3), 188-203. http://dx.doi.org/10.1080/08878730902974264

Grossman, P., Hammerness, K., McDonald, M., \& Ronfeldt, M. (2008). Constructing coherence: Structural predictors of perceptions of coherence in NYC teacher education programs. Journal of Teacher Education, 59(4), 273-287. http://dx.doi.org/10.1177/0022487108322127

Haberman, M. (1995). Star teachers of children in poverty. Indianapolis, IN: Kappa Delta Pi.

Howard, G. R. (2007). As diversity grows, so must we. Educational Leadership, 64(6), 16-22.

Irvine, J. J. (2003). Educating teachers for a diverse society: Seeing with the cultural eye. New York, NY: Teachers College Press.

Irvine, J. J., \& Armento, B. J. (2001). Culturally responsive teaching: Lesson planning for elementary and middle grades. New York, NY: McGraw-Hill.

Knoblauch, D., \& Woolfolk Hoy, A. (2008). "Maybe I can teach those kids.” The influence of contextual factors on student teachers' efficacy beliefs. Teaching \& Teacher Education, 24(1), 166-179. http://dx.doi.org/10.1016/j.tate.2007.05.005

Kozol, J. (1991). Savage inequalities: Children in America's schools. New York, NY: Harper Perennial.

Krei, M. S. (1998). Intensifying the barriers: The problem of inequitable teacher allocation in low-income urban schools. Urban Education, 33(1), 71-94. http://dx.doi.org/10.1177/0042085998033001005

Ladson-Billings, G. (1994). What we can learn from multicultural education research. Educational Leadership, $51(8), 22-26$. 
Ladson-Billings, G. (1999). Preparing teachers for diversity: Historical perspectives, current trends, and future directions. In L. Darling-Hammond, \& G. Sykes (Eds.), Teaching as the learning profession: Handbook of policy and practice (pp. 86-123). San Francisco: Jossey-Bass.

Ladson-Billings, G. (2000). Fighting for our lives: Preparing teachers to teach African American students. Journal of Teacher Education, 51(3), 206-214. http://dx.doi.org/10.1177/0022487100051003008

Ladson-Billings, G. (2001). Crossing over to Canaan: The journey of new teachers in diverse classrooms. San Francisco, CA: Jossey-Bass.

Lee, J., Tice, K., Collins, D., Brown, A., Smith, C., \& Fox, J. (2012). Assessing student teaching experiences: Teacher candidates' perceptions of preparedness. Educational Research Quarterly, 36(2), 3-19.

McFadden, C., \& Sheerer, M. (2006). A comparative study of the perceptions of teacher preparation faculty and school superintendents. Action in Teacher Education, 28(1), 51-71. http://dx.doi.org/10.1080/01626620.2006.10463567

McKinney, S. E., Haberman, M., Stafford-Johnson, D., \& Robinson, J. (2008). Developing teachers for high-poverty schools. Urban Education, 43(1), 68-82. http://dx.doi.org/10.1177/0042085907305200

Milner, H. R. (2005). Stability and change in US prospective teachers' beliefs and decisions about diversity and learning to teach. Teaching and Teacher Education, 21(7), 767-786. http://dx.doi.org/10.1016/j.tate.2005.05.010

Montecinos, C., Walker, H., Rittershaussen, S., Nuñez, C., Contreras, I., \& Solís, M. C. (2011). Defining content for field-based coursework: Contrasting the perspectives of secondary preservice teachers and their teacher $\begin{array}{llll}\text { preparation curricula. Teaching \& Teacher Preparation, 27(2), 278-288. } & \text {. }\end{array}$ http://dx.doi.org/10.1016/j.tate.2010.09.001

NCES. (1999). The condition of education. Retrieved from http://nces.ed.gov/pubsearch/pubsinfo.asp?pubid=1999022

NCES. (2005). The condition of education in brief. Retrieved from http://nces.ed.gov/pubsearch/pubsinfo.asp?pubid=2005095

Obiakor, F. E. (2001). It even happens in "good" schools: Responding to cultural diversity in today's classrooms. Thousand Oaks, CA: Corwin Press.

Obiakor, F. E. (2006). Multicultural special education: Culturally responsive teaching. Upper Saddle River, NJ: Prentice Hall.

Obiakor, F. E. (2008). The eight-step approach to multicultural learning and teaching (3rd ed.). Dubuque, IA: Kendall/Hunt.

Obiakor, F. E., Grant, P., \& Obi, S. O. (2010). Voices of foreign-born African American teacher educators in the United States. New York, NY: Nova Science Publishers.

Pohan, C. A. (1996). Preservice teachers' beliefs about diversity: Uncovering factors leading to multicultural responsiveness. Equity and Excellence in Education, 29(3), 62-69. http://dx.doi.org/10.1080/1066568960290310

Ray, A., \& Bowman, B. (2003). Learning multicultural competence: Developing early childhood practitioners' effectiveness in working with children from culturally diverse communities. Final report to the $\mathrm{A}$. L. Mailman Family Foundation. Center for Race, Class, and Culture in Early Childhood, Erikson Institute, Chicago, IL.

Risko, V. J. (2006). Facing teacher education challenges as an insider. Journal of Reading Education, 32(1), $5-12$.

Rushton, S. (2000). Student teacher efficacy in inner-city schools. Urban Review, 32(4), 365-383.

Rushton, S. (2001). Applying brain research to create developmentally appropriate learning environments. Young Children, 56(5), 76-82.

Ryan, S., Ackerman, D. J., \& Song, H. (2005). Getting qualified and becoming knowledgeable: Preschool teachers' perspectives on their professional preparation. Manuscript. Rutgers, The State University of New Jersey.

Singh, D. K., \& Stoloff, D. L. (2006). What do teacher candidates have to say about their clinical experiences? Paper presented at the Annual Meeting of the Association of Teacher Educators (ATE), Atlanta, GA. 
Siwatu, K. O. (2006). Preservice teachers' culturally responsive teaching self-efficacy and outcome expectancy beliefs: The role of multicultural and racial attitudes. Paper presented at the annual Texas Tech University, College of Education Research Conference, Lubbock, TX.

Siwatu, K. O. (2007). Preservice teachers' culturally responsive teaching self-efficacy and outcome expectancy beliefs. Teaching and Teacher Education, 23(7), 1086-1101. http:dx.doi.org/10.1016/j.tate.2006.07.011

Sleeter, C. E. (2008). An invitation to support diverse students through teacher education. Journal of Teacher Education, 59(3), 212-219. http://dx.doi.org/10.1177/0022487108317019

Tillman, L. C. (2003). From rhetoric to reality? Educational administration and the lack of racial and ethnic diversity within the profession. University Council for Educational Administration Review, 45(3), 1-4.

Ukpokodu, O. (2004). The impact of shadowing culturally different students on preservice teachers' disposition toward diversity. Multicultural Education, 12(2), 19-28.

Villegas, A. M. (2007). Dispositions in teacher education: A look at social justice. Journal of Teacher Education, 58(5), 370-380. http://dx.doi.org/10.1177/0022487107308419

Villegas, A. M., \& Lucas, T. (2002). Educating culturally responsive teachers. Albany, NY: State University of New York Press.

Weisman, E. M., \& Hansen, L. E. (2008). Student teaching in urban and suburban schools: Perspectives of Latino preservice teachers. Urban Education, 43(6), 653-670. http://dx.doi.org/10.1177/0042085907311834

Yeo, F. L. (1997). Inner-city schools, multiculturalism, and teacher education. New York, NY: Garland.

Zeichner, K., \& Hoeft, K. (1996). Teacher socialization for cultural diversity. In J. S. Kula (Ed.), Handbook of research on teacher education (2nd ed.) (pp. 525-547). New York, NY: Macmillan.

\section{Copyrights}

Copyright for this article is retained by the author(s), with first publication rights granted to the journal.

This is an open-access article distributed under the terms and conditions of the Creative Commons Attribution license (http://creativecommons.org/licenses/by/3.0/). 